\title{
the brownies' book: du bois e a construção de uma referência literária para identidade negra infanto-juvenil
}

\author{
valter roberto silvério ${ }^{1}$ \\ universidade federal de são carlos, são carlos, brasil \\ orcid id: https:/ / orcid.org/0000-0003-1715-4535
}

\section{resumo}

No período de janeiro de 1920 a dezembro de 1921 uma cooperação entre Jessie Fauset, Augustus Dill e W.E.B. Du Bois resultou na publicação denominada de "The Brownies' Book" (TBB) a primeira publicação para crianças e jovens negros, e não brancos (colored people), norte-americanos. A criação do "The Brownies' Book" (TBB) foi um evento pioneiro na literatura afro-americana em geral, pois foi o primeiro periódico composto e publicado por afro-americanos para crianças negras que, até então, procuravam em vão material que incluíssem uma perspectiva de sua experiência e história. $\mathrm{O}$ artigo, portanto, parte do pressuposto de que os TBB foram um dos prenúncios do movimento denominado de Renascença do Harlem se constituindo em uma materialização literária infanto-juvenil do caminho rumo à filosofia do Novo Negro (New Negro) na perspectiva do filósofo Alain Locke. O que estava sendo formulado era, tanto a desconstrução dos estereótipos associados ao negro quanto a projeção/criação ativa de uma identificação positiva com a sua comunidade local e de origem ancestral. As estratégias discursivas e práticas de desracialização propostas para "os filhos do sol", como W.E.B. Du Bois os chamava, para deixarem de se ver "através dos olhos dos outros" (Du Bois, 1903).

palavras chave: brownies' book; criança negra; literatura infanto-juvenil afro-americana; new negro; identidade.

\section{the brownies' book: du bois y la construcción de una referencia literaria para la identidad negra infanto-juvenil}

\section{resumen}

En el período de enero de 1920 a diciembre de 1921, una cooperación entre Jessie Fauset, Augustus Dill y W.E.B. Du Bois resultó en la publicación llamada "The Brownies' Book" (TBB), la primera publicación para niños y jóvenes negros y no blancos (personas de color) de América del Norte. La creación de "The Brownies 'Book" (TBB) fue un evento pionero en la literatura afroamericana en general y, más específicamente, en el campo de la literatura infantil afroamericana, ya que fue la primera revista compuesta y publicada por afroamericanos para niños negros que, hasta entonces, buscaban en vano material que incluyera una perspectiva de su experiencia e historia. El artículo, por tanto, asume que los TBBs fueron uno de los precursores del movimiento llamado Harlem Renaissance, constituyendo una materialización literaria infantil del camino hacia la filosofía del Nuevo Negro (New Negro) en la perspectiva del filósofo Alain Locke. Lo que se estaba formulando era tanto la deconstrucción de los estereotipos asociados con los negros como la proyección/creación activa de una identificación positiva con su comunidad local y ancestral. Así, uno de los aspectos importantes es identificar, después de la Primera Guerra Mundial, las estrategias discursivas y las prácticas de des-racialización propuestas para "los

\footnotetext{
${ }^{1}$ E-mail: diasporizando@gmail.com
} 
the brownies' book: du bois e a construção de uma referência literária para identidade negra infantojuvenil

hijos del sol", como los llamó W.E.B. Du Bois, para dejar de verse a sí mismos "a través de los ojos de otros" (Du Bois, 1903).

palabras clave: brownies' book; niño negro; literatura infantil afroamericana; new negro; identidad.

\section{the brownies' book: du bois e a construção de uma referência literária para identidade negra infanto-juvenil}

\section{abstract}

In the period from January 1920 to December 1921 a cooperation between Jessie Fauset, Augustus Dill and W.E.B. Du Bois resulted in the publication of a periodical called "The Brownies' Book" (TBB) the first publication for North American black, and not white (colored people) children and young people. The creation of "The Brownies' Book" (TBB) was a pioneering event in African American literature in general and, more specifically, in the field of African American children's literature, as it was the first periodical composed and published by African Americans for black children who, until then, searched in vain for material that included a perspective on their experience and history. This article argues that the TBBs were one of the harbingers of the movement called the Harlem Renaissance, constituting a children's literary materialization of the path towards the emergence of what the philosopher Alain Locke called the New Negro. What was being formulated was both the deconstruction of stereotypes associated with blacks and the active projection/creation of a positive identification with their local and ancestral community. This paper seeks to identify the post-WWI discursive strategies and practices of de-racialization proposed for "the children of the sun", as W.E.B. Du Bois called them, in order to stop seeing themselves "through the eyes of others" (Du Bois, 1903).

keywords: brownies' book; black child; african american children's literature; new negro; identity. 
the brownies' book: du bois e a construção de uma referência literária para identidade negra infanto-juvenil

\section{antecedentes contextuais do surgimento dos brownie's book}

Entre o final da Guerra Civil americana (1865) e o final da primeira Guerra Mundial (1919), os EUA passaram por intenso processo de transformações políticas, econômicas, culturais e sociais. A representação de Du Bois, do que ele metaforicamente denominou de "color line", demarcou que o problema do século $\mathrm{XX}$ era a linha da cor, primeiro, em referência às iterações sociais entre negros e brancos nos Estados Unidos, em The Philadelphia Negro (1899); e, posteriormente, nas iterações sociais mundiais entre colonizadores brancos e colonizados nãobrancos, na First Pan African Conference, em julho de 1900, no discurso dirigido às nações do mundo ${ }^{2}$.

Nascido três anos após o ato formal de emancipação dos escravos no Sul dos EUA, em 1868, e concluindo seu doutorado em Harvard publicado em 1895, um ano antes da decisão Plessey versus Fergusson. É possível, por meio da leitura da obra de Du Bois, acompanhar todos os retrocessos e implicações daquela decisão de 1896, a qual em síntese significou que uma distinção legal entre as "raças" branca e preta - uma distinção que é fundada na cor das duas "raças", e que sempre deve existir enquanto os homens brancos se distinguem da outra "raça" pela cor - não tem tendência a destruir a igualdade legal das duas raças... “O objetivo da [Décima Quarta] Emenda era sem dúvida impor a igualdade absoluta das duas raças perante a lei, mas na natureza das coisas não poderia ter como objetivo abolir as distinções baseadas na cor, ou impor o social, distinto da igualdade política, ou uma mistura das duas 'raças' em termos insatisfatórios para ambos ${ }^{3 "}$.

\footnotetext{
${ }^{2}$ A expressão "The Color Line" deu título a um artigo de Frederick Douglas publicado em 1881 na The North American Review, vol. 132, pp. 567-577. No qual Douglas comparou a linha de cor a uma doença social no âmbito da moral. Du Bois ampliou o significado ao estabelecer que o colonialismo e a cultura imperialista provocará uma divisão global em povos brancos e nãobrancos.

${ }^{3}$ Speaking for a seven-person majority, Justice Henry Brown wrote:

"That [the Separate Car Act] does not conflict with the Thirteenth Amendment, which abolished slavery... is too clear for argument... A statute which implies merely a legal distinction between the white and colored races -- a distinction which is founded in the color of the two races, and which must always exist so long as white men are distinguished from the other race by color --
} 
the brownies' book: du bois e a construção de uma referência literária para identidade negra infantojuvenil

Em síntese e na prática, a decisão estabeleceu o princípio de "separados, mas iguais", impondo a discriminação com base na cor como fundamento da negação da igualdade política. No Brasil, a legislação que organizou o processo de desescravização foi extremamente detalhada no seu objetivo de preservar os privilégios brancos e primou, a qualquer custo, em retardar a inclusão dos negros.

O primeiro livro de Du Bois, The Supression of Slave Trade (1896), apresentado como sua tese de doutoramento na Universidade de Harvard, nos coloca diante de um paradoxo que acompanhou os processos de "abolição" da escravatura no continente americano: "o comércio de escravos floresceu sob o disfarce de sua repressão". A abordagem inovadora de Du Bois coincidiu exatamente com o momento da história americana em que o regime legal de segregação conhecido como Jim Crow foi formalizado em 1896, sancionado pela Suprema Corte vinte anos após o final do processo conhecido nos EUA como Reconstrução. Na sequência, em 1899, Du Bois publica The Philadelphia Negro: a Social Study, que, segundo Bobo (2007), é uma pesquisa que detalha os efeitos da doutrina do "separado, mas igual", que impossibilitou o pleno e igual acesso da comunidade negra às políticas públicas.

O argumento do artigo é que no plano prático a doutrina do "separado, mas igual" representou a construção intencional de assimetrias de acesso entre brancos e negros à justiça, ao voto, às políticas públicas em especial a educacional. A criação do The Brownies' Book (TBB), enquanto o primeiro periódico composto e publicado por afro-americanos para crianças negras, respondia a uma conjuntura de época atuando na construção de uma identificação positiva com sua comunidade local e de origem ancestral, na desconstrução dos estereótipos associados ao negro e pavimentando o caminho rumo ao movimento New Negro do Harlem Renaissance; isto é, um movimento de renascimento intelectual e cultural com ênfase na música, dança, arte, moda, literatura, teatro produzido por afro-americanos centrado no Harlem, Manhattan, Nova York, entre 1920 e 1930.

has no tendency to destroy the legal equality of the two races... The object of the [Fourteenth] Amendment was undoubtedly to enforce the absolute equality of the two races before the law, but in the nature of things it could not have been intended to abolish distinctions based upon color, or to enforce social, as distinguished from political equality, or a commingling of the two races upon terms unsatisfactory to either." 


\section{aspectos da filosofia social e o lugar da educação em du bois}

As várias análises das contribuições de Du Bois apresentam, primeiramente, uma distinção entre seus estudos científicos sociais e estudos históricos. Os primeiros estariam preocupados com o progresso social, econômico e político e as condições que geravam a estagnação e o retrocesso dos afro-americanos. Os últimos se debruçaram sobre os caminhos do desenvolvimento dos afro-americanos, especialmente em termos da agência incorporada em suas ações individuais e coletivas. Em sua articulação, seus escritos demonstram uma impressionante coerência na manutenção de seu foco na observação, tanto dos obstáculos à mobilidade ascensional quanto das ações práticas de "promoção da elevação social" em direção da realização da justiça social para os negros.

Para Du Bois, o Sul branco, ao ser obrigado a abdicar do ideal e das práticas escravistas, subitamente fortaleceu e afirmou, em contraposição, o preconceito e a discriminação racial como fundamentos cristalizados em leis em meio ao profundo processo de reconfiguração do modo de produzir os bens materiais que implicavam em novas relações econômicas, políticas e culturais. Dois eventos marcantes protagonizados por Du Bois ocorrem em 1909: a publicação da biografia de John Brown 4 e sua participação na formação da Associação Nacional para o Avanço das Pessoas de Cor (NAACP). Associação que se dedicou a organizar campanhas contra os frequentes linchamentos como uma das frentes de luta que antecederam o planejamento em direção ao fim da segregação legal através do que passou a ser chamado de Movimento dos Direitos Civis, o qual restabeleceu a igualdade jurídica entre negros e brancos na Lei dos Direitos Civis de 1964 e na Lei dos Direitos de Voto de 1965.

Ao olharmos retrospectivamente a criação, em 1910, o magazine The Crisis: a record of darker races, por Du Bois e outros membros, como uma revista da NAACP preocupada, tanto em denunciar as injustiças sociais com base no pertencimento racial, como em oferecer alternativas para a construção da fraternidade humana e contra o perigo do preconceito e da discriminação raciais, como anunciadas na sua

\footnotetext{
${ }^{4}$ Na história da escravidão e seu legado, John Brown aparece como um herói abolicionista cujas ações precipitaram parcialmente a Guerra Civil norte-americana. A biografia escrita por Du Bois descreve Brown de forma estimulante.
} 
the brownies' book: du bois e a construção de uma referência literária para identidade negra infantojuvenil

fundação. A repercussão pública do magazine o transformou em uma das publicações mais influentes dos EUA.

Entre 1910 e 1921, o The Crisis abordou os principais problemas que atravessavam a vida dos negros na América, inclusive dedicando edições especiais para temas como sufrágio feminino, educação, crianças, trabalho, guerras, entre outros temas. Desde o início, a revista preocupou-se com a produção de uma perspectiva que reconhecesse a criação estético-cultural negra e favorecesse a emergência de uma identidade negra positiva para os filhos dos ex-escravos.

A revista, portanto, forneceu uma alternativa necessária aos estereótipos raciais e silêncios da grande imprensa publicando, a cada mês, relatos edificantes de realizações de afro-americanos e, também, denúncias sistemáticas que demonstravam os impactos perversos da discriminação racial, em especial os linchamentos. Dentre as edições especiais, aquela de maior sucesso era a dedicada às crianças, o que levou Du Bois a declarar no The Crisis, em outubro de 1919, o seguinte:

em relação ao The Children Crisis... é o número mais popular do ano - isto é, faz o maior apelo aos nossos leitores. É assim que deve ser. Claro, estamos e devemos estar interessados em nossos filhos acima de tudo, se amamos nossa raça e humanidade... (Diggs, 1976, p. 390).

Antes do anúncio do lançamento, em cooperação com o magazine The Crisis, do The Brownie's Book (Os filhos do Sol), nos termos dos autores, uma revista projetada com alegria e beleza, lidando com a felicidade, riso e emulação, para crianças dos seis aos dezesseis anos (Diggs, 1976, pp. 390-391).

A revista para "os filhos do sol" estava em total consonância com as análises de Du Bois no período; ao focalizar no tratamento amplo dispensado por ele à educação do negro, podemos situar, por um lado, os contornos dos dilemas econômicos e políticos que estavam na base de sua filosofia social e, por outro lado, as soluções práticas que atenuassem os impactos/dilemas da transição entre a escravidão e a liberdade em um contexto de mudanças atravessado pelo ódio, o preconceito, a discriminação racial legal, a ilegalidade e a competição impiedosa.

O ideário da supremacia racial branca que atravessava a sociedade global foi objeto de reflexão de Du Bois que, embora reconhecesse e utilizasse as pesquisas 
empíricas utilizando-se dos métodos mais avançados à época; observou, vis-à-vis ao ativismo, certas limitações das mesmas e, ao mesmo tempo, a necessidade de incorporar alguma inovação filosófica metodológica para interpretar os humanos especialmente em três aspectos que eram os seguintes: humanidade, subjetividade e dever. Com base nas seguintes questões que orientavam as reflexões do autor, conforme Wilson (2014, p. 47): “1. Por que Du Bois quis enfatizar tanto o pressuposto da humanidade comum quanto a subjetividade? 2. Poderiam as técnicas empíricas descobrir a humanidade fundamental dos negros?"

A questão da humanidade das pessoas africanas ganha prioridade em sua reflexão em um contexto no qual ela era alvo de questionamento pela ciência. Du Bois enfatizou tanto os pressupostos da humanidade quanto da subjetividade. $O$ argumento, no primeiro caso, enfatizava que o negro era "um membro constituinte da grande família humana" e era fundamentalmente semelhante aos brancos em termos das capacidades humanas básicas para desenvolver-se de todas as maneiras possíveis e imagináveis no período. Sem tal suposição, a pesquisa seria considerada de importância menos premente (Atlanta Conferences, parágrafos 8-9).

Em relação à subjetividade, o foco era na experiência dos afro-americanos, especialmente no que se referia às vivências com preconceito e a discriminação racial em que se poderia observar as possibilidades de construção de alternativas para um futuro de liberdade e prosperidade. Dois aspectos da noção de subjetividade são fundamentais em Du Bois: a agência humana e os ideais e valores.

Em relação às ações humanas, ele reconheceu que elas deveriam ser apreendidas em termos de "ritmos": primário e secundário. Em "ritmo" primário elas poderiam ser interpretadas mecanicamente como o resultado da aplicação das leis sociais (taxas de natalidade e mortalidade), por exemplo. Mas, crucialmente, os humanos seriam compreendidos em termos de um "ritmo secundário" - um ritmo de livre arbítrio pelo qual os indivíduos podem decidir e agir de maneiras conscientemente contrárias às leis determinísticas. Assim, os ideais e valores que situavam o grupo negro na condição de não humanidade deveriam ser substituídos por aqueles que "os exortavam a viverem de acordo com padrões de excelência e a lutarem por horizontes para além daqui e agora da vida diária" (Wilson, 2014, p. 47. 
the brownies' book: du bois e a construção de uma referência literária para identidade negra infantojuvenil

Tradução livre). O processo de perseguição de ideais, mesmo que não plenamente alcançados, teria um efeito edificante, no sentido espiritual e intelectual, sobre aqueles que lutam tendo por referência o futuro. Por causa de sua agência intrínseca como humanos, os negros podiam entender e mudar a si mesmos e, por extensão, podiam mudar o mundo.

Em Du Bois, portanto, o uso das técnicas de pesquisa social ou mais precisamente os resultados mensurados e mensuráveis das condições de vida, por exemplo, de brancos e negros, eram limitados por eles não "conseguirem" capturarem tanto a atividade política da contenção dos mecanismos "democráticos" de mobilidade social quanto as ações do grupo subalternizado na ampliação do espaço normativo em direção à justiça social. Em termos práticos, para Du Bois não haveria coincidência entre os objetivos perseguidos pela pesquisa social e pelo ativismo dos negros. Assim, a questão é a seguinte: como seria possível para a pesquisa social com suas técnicas supostamente neutras axiologicamente contribuírem para a construção de uma sociedade justa guiada por valores e ideais normativos que incorporassem os negros e suas contribuições específicas como parte de uma humanidade comum?

Du Bois deu a entender que havia limitações das técnicas de investigação social quando pensadas para orientar o ativismo. Seus limites estavam localizados naquilo que também distinguia sua utilidade: apenas o que poderia ser operacionalizado por meio de indicadores empíricos poderia ser estudado. Dito de outra forma, os argumentos filosóficos podem sustentar os ideais e valores, mas eles não poderiam ser corroborados empiricamente. Não que fossem completamente inobserváveis (Williams, 2014). Em termos educacionais, por exemplo, as necessidades dos filhos dos ex-escravos, no pós-abolição, eram socialmente diferentes das dos filhos de ex-senhores.

As limitações da ciência expressa por Du Bois foi o que o levou à reflexão sobre o dever que envolveria o fazer de valor moral sem consideração, ou sem levar em conta, o interesse ou ganho pessoal. Para ele, o dever normalmente se concentrava em agir intencional e resolutamente de maneira a aumentar a liberdade e a igualdade para os negros, e para as pessoas de cor em geral, em face da opressão 
cruel. O dever envolvia sacrifício pessoal, daqueles que tiveram acesso à educação superior, para o bem maior das comunidades negras. Ele frequentemente encorajava a elite negra com educação universitária a cumprir seu dever para com sua comunidade de origem, fornecendo exemplos morais de comportamento e orientando atividades públicas e privadas em apoio à igualdade e liberdade (Williams, 2014).

\section{ver a vida com os próprios olhos}

É com base no percurso acima que se deu a leitura do capítulo "Sobre a Instrução dos Negros" ([1903]; 1999, pp. 143-162), no qual Du Bois reconstruiu alguns momentos decisivos que foram representativos das possibilidades abertas e das opções políticas tomadas em termos de política educacional, como seguem:

1) Do final da guerra civil americana (1865) e 1876; viveu-se o período de tentativas incertas e lenientes: escolas militares, escolas missionárias e as escolas do Freedmen's Bureau ${ }^{5}$ em que a desorganização caótica superava o planejamento e a busca de cooperação na solução do problema da educação dos negros;

2) Entre 1875 e 1885 foram dez anos de esforços construtivos: fundaram-se escolas e instituições universitárias para os libertos e, nessas últimas, prepararam professores para atuarem nas instituições públicas;

3) A revolução industrial que ocorreu no sul dos EUA, a partir de 1875 ganhando maior visibilidade entre 1885-1895, desvendou, por um lado, os obstáculos à integração dos ex-escravos e seus filhos frente ao imaginário e ressentimentos que alimentavam os preconceitos dos senhores do Sul e, por outro lado, a fragilidade das instituições negras fundadas - escolas primárias, escolas secundárias, instituições de ensino superior HBCU's (Historical Black Colleges and Universities), as quais se apresentavam como inadequadas às novas condições sociais.

A abolição da escravatura e o estabelecimento de um regime de trabalho livre nos EUA, em especial no sul do país e, também, em vários países de origem colonial, colocou de imediato a questão da integração social dos descendentes de africanos, filhos de libertos e/ou ex-escravizados. A coincidência entre a emergência de uma

\footnotetext{
${ }^{5}$ Com a crescente necessidade de convocar soldados negros para reforçarem as tropas do norte contra o sul conflagrado e pressionado pelos abolicionistas radicais do Republican Party, o Presidente Lincoln abandonou os projetos de emigração da população negra do país, proclamando, a partir de 1863, a emancipação dos escravos nos estados rebeldes. Nota 2, p. 64, W.E.B. Du Bois, As almas da gente negra, 1999, edição brasileira.
} 
the brownies' book: du bois e a construção de uma referência literária para identidade negra infantojuvenil

sociedade industrial e o estabelecimento de uma ordem social competitiva significou, no caso norte-americano, um intenso debate sobre a educação enquanto política pública de ajustamento social que responderia às necessidades dessa nova sociedade.

O contexto norte-americano, como de resto outros territórios "nacionais", vivia uma contradição no pós-abolição a qual, do ponto de vista prático, pode ser resumida da seguinte forma: enquanto as ciências sociais da época iniciavam sua idealização em termos de acomodação (de conflitos étnico-raciais), aculturação (a ideia de que a cultura urbana-industrial uniformizaria a sociedade racialmente diferente), o que levaria à integração econômica de todos em uma sociedade de abundância e igualdade, a experiência vivida da população negra era de exposição perene às práticas de exclusão legal, discriminação ostensiva e representações estéticas depreciativas.

O raciocínio básico era que as condições proporcionadas pela sociedade urbano-industrial levariam, por um lado, a uma cultura moderna na qual a educação enquanto política pública teria a função de inculcar um conjunto de atitudes e valores nas novas gerações e, por outro lado, como desdobramento caminharíamos em direção de um humanismo color-blind.

O pressuposto de apagamento da herança étnica (origem cultural) e racial (a cor transformada em diferenças de aptidão intelectual) obviamente não poderia se realizar num quadro em que a promessa de acesso igualitário às políticas públicas, em especial, como condição para a realização do bem comum, foi sistematicamente impedida, tanto nas práticas cotidianas quanto na construção da arquitetura social hierárquica (política e jurídica). É neste quadro que Du Bois vai transitar entre a identificação de uma ideologia nacional que a um só tempo convoca a uma comunhão de valores, atitudes e sentimentos comuns e, por outro lado, estabelece o impedimento da participação efetiva de muitos com base nas marcas corpóreas.

Du Bois vai notar essa contradição entre o discurso que irá se transformar em hegemônico na sociologia (acomodação-aculturação-integração) e as práticas políticas excludentes de acesso aos bens comuns e, também, a formalização jurídica- 
legal da segregação com base no pertencimento étnico-racial, isto é, sistemas legais racializados, como o sistema Jim Crow ${ }^{6}$.

Neste sentido, o periódico “The Brownies' Book” é uma resposta pragmática a um contexto histórico informado pela ideia de supremacia branca, a qual ao estabelecer jurídica e politicamente a inferioridade negra negava, aos últimos, as possibilidades de superação das iniquidades sociais. A "raça" enquanto signo organizava a hierarquia de acesso aos bens culturais sociais em geral e, em especial, à política pública de educação. Du Bois questionou, por um lado, as escolas "racialmente" segregadas e, por outro lado, a ideia de que aos negros caberia prioritariamente o ensino industrial.

A resposta política à abolição constitucional foi a segregação legal com suas implicações em relação às restrições aos direitos de cidadania como, por exemplo, o não acesso ao voto. A obra acadêmica de Du Bois é, ao mesmo tempo, um documento vivo da forma como as possibilidades de constituição de uma democracia efetiva no pós-abolição foram frustradas e uma alternativa de interpretação da forma como o ativismo negro construiu caminhos para assegurar a existência da população afro-americana frente ao ódio racial, a eliminação física por meio dos linchamentos e a contenção de seu acesso igualitário às políticas públicas.

the brownies' book: du bois e a construção de uma referência literária para identidade negra infanto-juvenil

Liss (1998) argumenta que Du Bois é considerado um dos intelectuais que, na virada do século XIX para o XX, frente ao uso generalizado pelos cientistas em geral de "raça" como um critério de classificação das diferenças humanas visíveis,

\footnotetext{
${ }^{6}$ Entre 1870 e 1960, as leis Jim Crow mantiveram uma hierarquia racial cruel nos estados do sul dos EUA, contornando as proteções que tinham sido implementadas depois do fim da Guerra Civil - como a $15^{\mathrm{a}}$ Emenda, que há 150 anos já concedia aos negros o direito ao voto. As leis discriminatórias negavam os direitos aos negros, submetiam-nos à humilhação pública e perpetuavam a sua marginalização econômica e educacional. Qualquer um que desafiasse a ordem social enfrentava menosprezo, assédio e assassinato. $\mathrm{O}$ termo tem origem na década de 1820, quando o comediante branco Thomas Rice criou a personagem "Jim Crow". Esta personagem estereotipada tornou-se numa figura comum nos espetáculos teatrais de comédia - e um apelido amplamente usado para descrever pessoas de ascendência negra. nationalgeographic.com.
} 
the brownies' book: du bois e a construção de uma referência literária para identidade negra infantojuvenil

se contrapôs a tal perspectiva argumentando que "raça" era algo além de tais características visíveis. Contra a desumanização, estigmatização e animalização caricatural do fenótipo dos descendentes de africanos, Du Bois irá demonstrar a importância da contribuição da África, deslocando a compreensão racializada eurocêntrica para uma compreensão pluralista cultural da humanidade7 .

Nas primeiras décadas do século XX Du Bois propôs, por um lado, uma alternativa a tais caracterizações, as quais, em geral, eram feitas por meio de caricaturas e ridicularizações e imitações vulgares intencionais na música popular nos minstrels shows e nas coon songs, como bem demonstra o filme de Spike Lee $A$ hora do show (Bamboozled), lançado em 2000; e, por outro lado, formulou respostas, dentre elas, a criação dos The Brownies Book. A figura $n^{\circ} 1$ é uma das imagens produzidas por brancos, que circulava na forma de postal, no qual podemos observar o tipo de representação caricatural e racista das primeiras décadas do século XX.

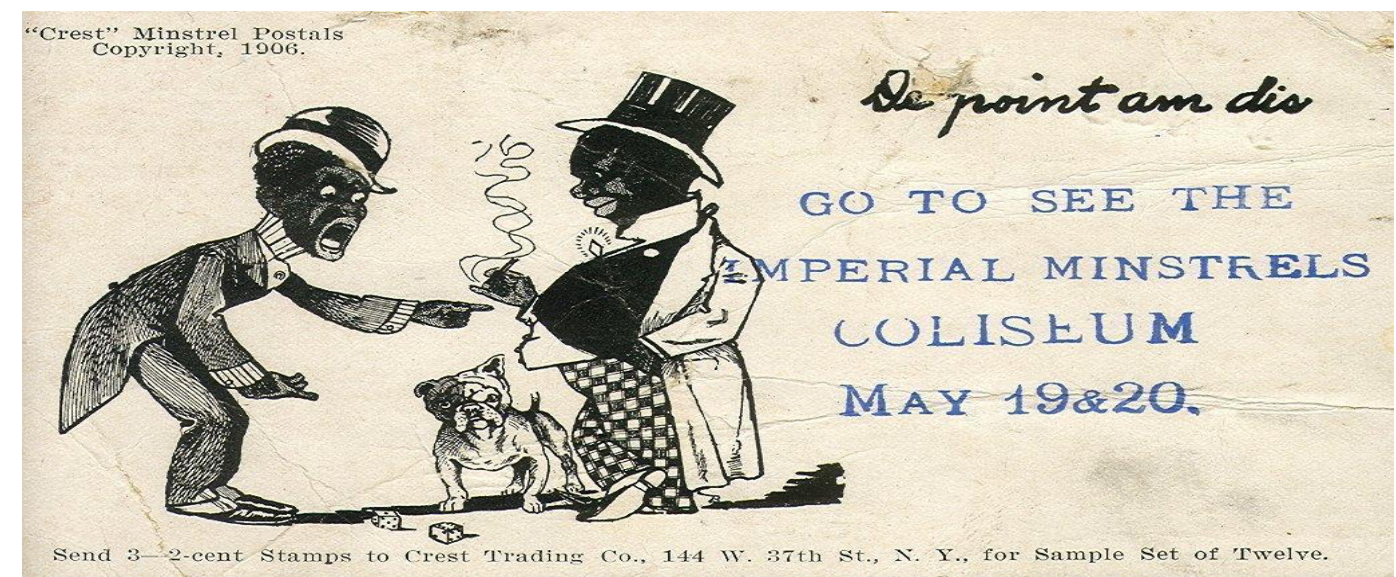

Figura 1: "Crest" Minstrel Postals - Copyright, 1906

Fonte: https://commons.wikimedia.org/wiki/File:ImperialMinstrelsPostcard.jpg

A questão de Du Bois era a seguinte: dada a crescente ausência de condições sociais básicas para a população negra, a circulação crescente de representações racialmente depreciativas e considerando sua diferenciação interna, como seria possível uma política que contrastasse efetivamente com a supremacia branca?

Sua resposta à pergunta foi relativamente direta:

\footnotetext{
${ }^{7}$ Liss (1998), também, chama a nossa atenção para a ausência nos debates da virada do século XX para o século XXI das contribuições de Frantz Boas e Du Bois, dada as similaridades de questões da virada do século XIX para o XX.
} 
Pelo desenvolvimento desses grupos raciais, não como indivíduos, mas como raças. ...Para o desenvolvimento do gênio negro, da literatura e arte negras, do espírito negro... somente negros ligados e unidos, negros inspirados por um vasto ideal, podem elaborar em sua plenitude a grande mensagem que temos para a humanidade (Du Bois, 1897a, p. 10).

O novo caminho acerca da moderna identidade negra nos termos de Du Bois é a sua retirada do exílio imposto pelas noções europeias dominantes de verdade, beleza e moralidade que o definiram desde o iluminismo como portador de uma consciência infeliz, como uma marca do seu fracasso em cumprir o mandato da modernidade e da modernização. Contra essa proposição, Gikandi (2005, p. 1) argumenta que

Du Bois parecia acreditar que na arte, e especialmente no que ele via como a natureza essencialmente artística do africano, poderia ser encontrada uma saída significativa da prisão da racionalidade, um desvio para uma consciência feliz, por assim dizer. Assim, em vez de ver as questões da arte e da política separadas na mente de Du Bois, mostrarei que a África - e as formas estéticas que gerou forneceram um recurso importante no desenvolvimento de uma crítica da modernidade.

A contribuição para a humanidade, a mensagem, o espírito da "raça" estava presente na música, na poesia e na emergente literatura negra ou afro-americana que trazia em seu conteúdo tanto a memória ancestral da África quanto o sofrimento das condições de trabalho e existência na América satirizadas e ridicularizadas pela violenta opressão e dominação articulada pela supremacia branca na forma de negação de direitos e da própria existência subjetiva.

A reconstrução da contribuição da África para a humanidade era, portanto, uma necessidade incontornável para a identificação positiva da criança e do jovem negro e, ao mesmo tempo, a possibilidade de se contrapor às caricaturas e ridicularizações supremacistas brancas.

Nos termos de Hopkins (1988, prefácio), a ficção é de grande valor e importância para qualquer pessoa como preservadora de maneiras e costumes religiosos, políticos e sociais. É um modo de construir e dar sentido ao crescimento e desenvolvimento de geração em geração. Em seguida a autora afirma:

Ninguém fará isso por nós; devemos desenvolver nós mesmos os homens e mulheres que irão retratar fielmente os pensamentos e sentimentos mais íntimos do Negro com todo o fogo e romance que 
the brownies' book: du bois e a construção de uma referência literária para identidade negra infantojuvenil

jazem adormecidos em nossa história, e, ainda, não reconhecidos pelos escritores da raça anglo-saxônica8.

Qual seria, portanto, o conteúdo a ser desenvolvido para crianças negras que eram caricaturadas e ridicularizadas cotidianamente?

Para Du Bois, e seus colaboradores, a África era primariamente a terra dos negros e representava uma das populações mais antigas da humanidade. No entanto, o mundo moderno conheceu a África, não como a origem da humanidade e do desenvolvimento das instituições religiosas, políticas e sociais, mas o negro como escravo na América. As concepções distorcidas, portanto, geradoras de preconceitos, estavam no "apagamento" da história do continente africano e na ênfase da centralidade da Europa que eram os fundamentos da suposição generalizada, em todo mundo dominante que a cor era (é) uma marca de inferioridade.

É na confluência, portanto, do real significado de África para a humanidade (a proposta de Du Bois em $19099^{9}$ era elaborar uma enciclopédia) e nas respostas à questão do que era ser um negro nos EUA nos anos 1920 que surgiu The Brownies Book como uma resposta prática para a construção de uma identidade positiva para os "filhos do sol" como Du Bois denominava as crianças negras. A referência foi retirada do poema, que reproduzimos abaixo, de Fenton Johnson (1888-1958).

\section{Children of the Sun}

We are children of the sun, Rising sun! Weaving Southern destiny, Waiting for the mighty hour

When our Shiloh shall appear With the flaming sword of right, With the steel of brotherhood,

\section{Filhos do Sol}

Somos filhos do sol,

Sol Nascente!

Tecendo o destino do Sul,

Esperando pela hora poderosa

Quando nosso Shiloh ${ }^{10}$ deve aparecer

Com a espada flamejante do direito,

Com o aço da fraternidade,

\footnotetext{
${ }^{8}$ Pauline E. Hopkins, preface, Contending Forces: A Romance Illustrative of Negro Life North and South, 1900, by Pauline E. Hopkins. Oxford: Oxford UP, 1988.

${ }^{9}$ SILVÉRIO, V.R. O programa Brasil-África na construção da ideia de diáspora africana. Revista do PPGCS - UFRB - Novos Olhares Sociais | Vol.1 - n.1 - 2018, p. 131-162.

${ }^{10}$ Shiloh é uma palavra hebraica antiga e parece significar "aquele de quem é" ou "aquele que deve ser enviado" ou "o que lhe pertence". O nome aparece em Gênesis 49:10: O cetro não se afastará de Judá, nem um legislador entre seus pés, até que Shiloh venha; e a ele se reunirá o povo. https://christiananswers.net/dictionary/shiloh.html
} 
And emboss in crimson die

Liberty! Fraternity!

We are the star-dust folk,

Striving folk!

Sorrow songs have lulled to rest;

Seething passions wrought through wrongs,

Led us where the moon rays dip

In the night of dull despair,

Showed us where the star gleams shine,

And the mystic symbols glow-

Liberty! Fraternity!

We have come through cloud and mist,

Mighty men!

Dusk has kissed our sleep-born eyes,

Reared for us a mystic throne

In the splendor of the skies,

That shall always be for us,

Children of the Nazarene,

Children who shall ever sing

Liberty! Fraternity!

From The Book of American Negro

Poetry (Harcourt, Brace and Company, 1922)

edited by James Weldon Johnson. This poem

is in the public domain.
E estampado na matriz carmesim (vermelho forte) Liberdade! Fraternidade!

Nós somos o povo do pó estelar,

Esforçando-se, gente!

As canções de tristeza embalaram o descanso;

Paixões fervilhantes produzidas por erros,

Nos levou onde os raios da lua mergulham

Na noite de desespero monótono,

Nos mostrou onde o brilho das estrelas brilha,

E os símbolos místicos brilham -

Liberdade! Fraternidade!

Viemos através de nuvens e névoa,

Homens poderosos!

O crepúsculo beijou nossos olhos sonolentos,

Criou para nós um trono místico

No esplendor dos céus,

Isso sempre será para nós,

Filhos do Nazareno,

Crianças que sempre devem cantar

Liberdade! Fraternidade!

Extraído de The Book of American Negro Poetry (Harcourt, Brace and Company, 1922), editado por James Weldon Johnson. Este poema é de domínio público. ${ }^{11}$

Johnson se refere aos afro-americanos que começaram a se levantar da escuridão, um lugar que havia sido designado a eles por americanos brancos, e logo serão capazes de brilhar intensamente e mostrar todo o seu esplendor ao mundo ${ }^{12}$.

\section{objetivo e temas do magazine}

A gênese do magazine infantil, The Brownies Book (TBB), está relacionada à educação de futuros líderes jovens. Antes do seu lançamento, as crianças afroamericanas só podiam se ver "através dos olhos dos outros" - para usar a famosa frase de Du Bois em The Souls of Black Folk - se fossem retratadas. De acordo com as análises do período praticamente todo o material de leitura para crianças e jovens, desde livros, passando por periódicos infantis e livros didáticos, era permeado pelos valores e ideologias de uma tradição seletiva que garantiu a

\footnotetext{
${ }^{11}$ Disponível em: https:/ / poets.org/poem/children-sun

${ }^{12}$ Sachäffer, Christina. The Brownies' Book: Inspiring Racial Pride in African-American Children. Frankfurt am Main: Peter Lang, 2012, p. 50, nota 128.
} 
the brownies' book: du bois e a construção de uma referência literária para identidade negra infantojuvenil

hegemonia dos americanos brancos sobre os negros e ajudou a reforçar as hierarquias raciais promovendo os estereótipos anti-negros.

A concepção do TBB, para além de Du Bois, está associada a outros dois nomes fundamentais: Jessie Redmon Fauset e Augustus Granville Dill. Em especial a primeira, editora dos TBB, que trabalhou, também, como editora literária do jornal da NAACP, The Crisis, ambos sob a direção de W. E. B. Du Bois, entre 1919 e 1926. A análise da produção literária de Fauset, tanto pela quantidade quanto pela qualidade, que não é o objeto deste artigo, tem merecido maior atenção da literatura especializada ${ }^{13}$.

O período de publicação dos TBB foi entre janeiro de 1920 e dezembro de 1921. Ele tem sido interpretado como um evento pioneiro na literatura afroamericana em geral e, mais especificamente, no campo da literatura infantil, pois foi o primeiro periódico composto e publicado por mulheres e homens negros para crianças negras que, até então, procuravam em vão por material que incluísse uma perspectiva que falasse sobre a importância e glória dos povos descendentes de africanos. O fato é que a literatura especializada, também, tem analisado o surgimento do TBB como o prenúncio da Renascença do Harlem, pavimentando o caminho para a filosofia do Novo Negro de Alain Locke ${ }^{14}$, ampliando sua importância e significado.

No seu primeiro número em janeiro de 2020, os TBB anunciavam que eram uma revista mensal para os "filhos do sol" projetada para todas as crianças, mas especialmente para as nossas. E prosseguia:

Tem como objetivo ser uma coisa de felicidade e beleza, lidando com alegria, risos e emulação, principalmente, para crianças de seis a dezesseis anos.

Ele buscará ensinar o Amor Universal e a Fraternidade para todas as pessoas pequenas - pretas, marrons, amarelas e brancas.

Claro, fotos, histórias, cartas do pequeno, jogos e oh - tudo!"15.

${ }^{13}$ Omlinson, Susan."Teaching Jessie Fauset's Plum Bun." In Teaching the Harlem Renaissance: Course Design and Classroom Strategies. Edited by Michael Soto, 115-121. New York: Peter Lang, 2008; Wall, Cheryl. Women of the Harlem Renaissance. Bloomington: Indiana University Press, 1995.

${ }^{14}$ Locke, A. The New Negro: Voices of the Harlem Renaissance, New York: Touchstone, 1997.

15 "It aims to be a thing of joy and Beauty, dealing in Happiness, Laughter and Emulation, and especially for Kiddies from Six to Sixteen. It will seek to teach Universal Love and Brotherhood for all little folk-black and brown and yellow and white. Of course, pictures, stories, letters from little one, games and oh - everything!", The Brownies' Book - January, 1920. 
Ao comparar os TBB e Ebony ${ }^{16}$ Jr., Courtney Vaughn-Roberson e Brenda Hill (1989, pp. 494-510) concluem que ambas as publicações compartilham temas comuns e apresentam modelos fictícios e autênticos de negros de sucesso que lutam por identidade e propósito, sem rejeitar sua própria herança e valores culturais. As autoras, também, observam temas comuns entre os intelectuais e ativistas nos anos que antecederam o New Negro Movement como, por exemplo, a herança africana e afro-americana, a unidade afro-americana, a consciência racial e de classe, a origem geográfica e consciência racial, a educação e os valores, a lealdade familiar e os papéis de gênero ${ }^{17}$.

Estes são, precisamente, os temas que compunham a perspectiva de Du Bois e Fauset, que propunham uma representação positiva da beleza infantil negra em contraste com as caricaturas e representações desumanizantes que circulavam no período, como já mencionado anteriormente, como se pode observar na figura $\mathrm{n}^{\circ} 2$ abaixo.

\footnotetext{
${ }^{16}$ Em 1945, John H. Johnson publicou a primeira edição da revista Ebony, um periódico mensal voltado para leitores afro-americanos. Em 1973, a Johnson Publishing Company expandiu seu público leitor para incluir crianças, produzindo Ebony Jr.! Visando crianças negras na faixa de cinco a onze anos, a revista trazia histórias, quadrinhos, quebra-cabeças e desenhos animados. Seu conteúdo combinava elementos da cultura negra, história negra e currículo do ensino fundamental. A publicação permaneceu impressa até 1985 e foi ressuscitada online em 2007. Henderson, L. Ebony Jr.!: The Rises, Fall, and Return of Black Children's Magazine. Scarecrow Press, 2008.

${ }^{17}$ Vaughn-Roberson, and Hill, "The Brownies' Book and Ebony Jr.!: Literature as a Mirror of the Afro-American Experience". Williams-Sanchez, Valerie L. (2019) "The Brownies' Book," The Reading Professor: Vol. 42: Iss. 1, Article 5. Available at: https://scholar.stjohns.edu/thereadingprofessor/vol42/iss1/5
} 
the brownies' book: du bois e a construção de uma referência literária para identidade negra infantojuvenil

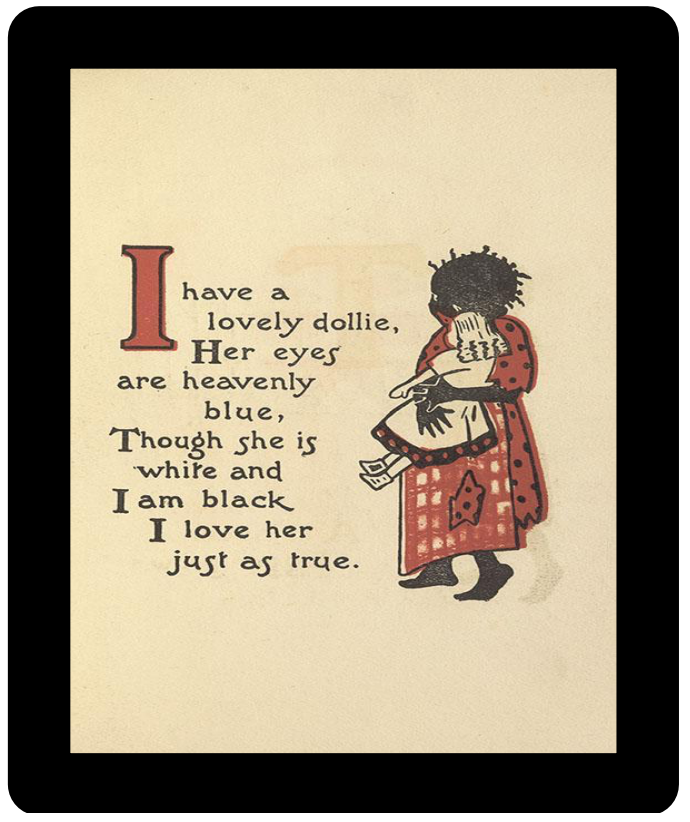

Figura 2: Anonymous Pickaninnies: Little Redskins, c. 1910 Stewart \& Co.39p175618

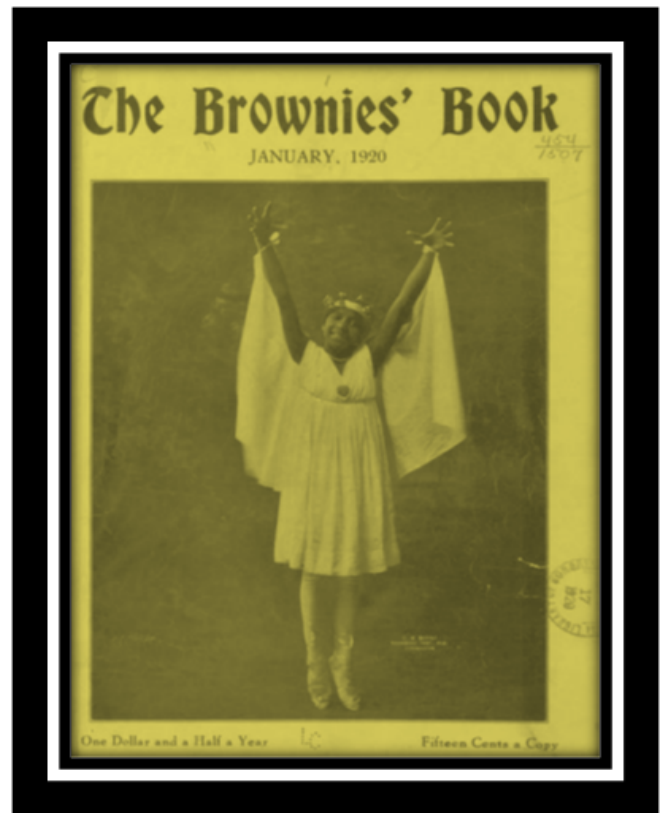

Figura 2: Cover Picture, photograph by Cornelius Marion Battey, TBB Jan. 1920: n. pag., print.

A imagem de uma linda menina negra associada à figura de um anjo que está na capa do primeiro número do TBB era inimaginável nos anos 1920 nos EUA, como demonstra a caricatura ao seu lado. Os retratos racistas de muitos livros infantis tinham como função promover a superioridade branca através de representações depreciativas que desumanizavam as crianças negras. As ilustrações distorcidas eram acompanhadas de um uso da língua de modo a caracterizar uma deficiência cognitiva e, também, mostravam as pessoas negras deformadas e exageradas. Assim, na capa do primeiro número do magazine Brownies Book, podemos observar sua orientação em contraste com as imagens estereotipadas larga e uniformemente reproduzidas nos jornais, revistas, livros, em especial os infantis e juvenis, nos quais a representação pictográfica dos negros em geral e, em especial das crianças negras, eram a regra.

Ao comentar a capa do primeiro número, Sachäffer (2012, p. 60) argumenta que:

Olhar para esta foto deve ter sido uma experiência única para os jovens leitores afro-americanos. Para destacar a beleza negra, os editores até usaram uma estampa colorida, e a pele da menina é mostrada em tons de marrom e laranja. No verso da capa, Du Bois

\footnotetext{
${ }^{18}$ https:/ / exhibits.uflib.ufl.edu/RacismRepresentation/racist-portrayals.html
} 
e Dill publicaram outro anúncio de sua publicação. Primeiro, eles proclamam: "Este é o livro dos Brownies"; "uma revista mensal para os filhos do sol"; "projetado para todas as crianças, mas especialmente para as nossas" 19 .

A preocupação com a edição do magazine, isto é, as imagens, o contraste entre as cores marrom e laranja, para destacar a beleza negra, deixa evidente a intenção dos propositores de alterar o curso da história dos preconceitos e estereótipos, nos termos da época, construindo uma identificação positiva para a criança negra a partir de seu grupo de referência ou, mais precisamente, da reconstituição/construção de valores associados tanto em relação à sociedade norte-americana que as rejeitavam, quanto em relação à África enquanto um continente que tinha uma história de que elas pudessem se orgulhar. Como se pode observar na figura $n^{\circ} 3$, a referência a Zaouditou ${ }^{20}$, Rainha dos Reis da Abissínia, Imperatriz da Etiópia.

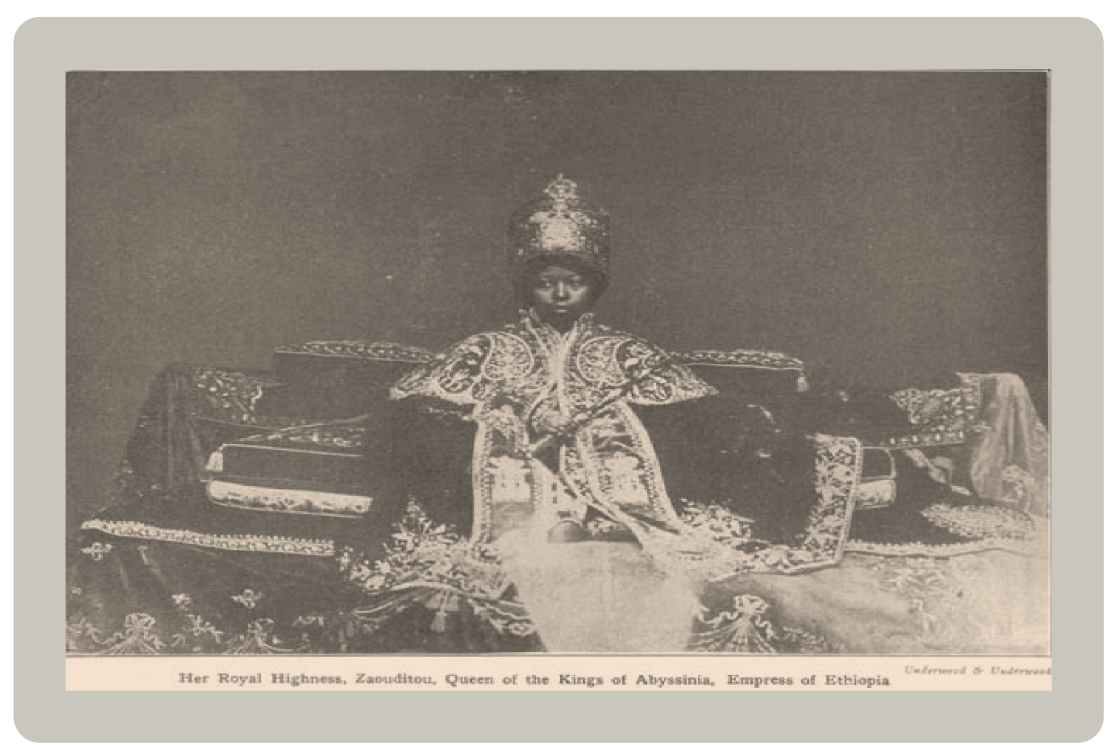

Figura 3: Frontispiece “The Empress Zaouditou,” photography by Underwood \& Underwood, TBB Jan. 1920, v. 2, print.

\footnotetext{
${ }^{19}$ Looking at this picture must have been a unique experience for the young African-American readership. To point out black beauty, the editors even used a color print, and the girl's skin is shown in shades of brown and orange. On the back of the cover, Du Bois and Dill printed another announcement of their publication. First, they proclaim: "This is The Brownies' Book;" "A Monthly Magazine For the Children of the Sun;" "Designed for All Children, but Especially for Ours."

${ }^{20}$ Nasceu como Askala Maryam, em 29 de abril de 1876 e morreu a 2 de abril de 1930, foi a Imperatriz da Etiópia de 1916 a 1930. A primeira chefe feminina de um país internacionalmente reconhecido na África nos séculos 19 e 20 e a primeira imperatriz reinante do Império Etíope. https://www.blackpast.org/global-african-history/empress-zewditu-1876-1930
} 
the brownies' book: du bois e a construção de uma referência literária para identidade negra infantojuvenil

A fotografia mostra "Sua Alteza Real, Zaouditou, Rainha dos Reis da Abissínia, Imperatriz da Etiópia", como as crianças podem ler na legenda (TBB Janeiro de 1920, p. 2). A Imperatriz está no centro da imagem, sentada em um trono feito de almofadas e cobertores valiosos e amplamente adornados. Seu traje é feito de um material caro e é bem decorado e bordado. Na cabeça, ela usa uma grande coroa e segura um cetro na mão. A Imperatriz está sentada em uma posição ereta, olhando graciosamente para a frente, mas não diretamente para o leitor. Esta fotografia apresenta aos jovens afro-americanos a realeza negra com a intenção de aumentar sua auto-estima, com a evidente intenção de demonstrar que a raça negra também pode reivindicar nobreza ${ }^{21}$.

As análises que focam o período procuram analisar a presença do discurso racial em livros de literatura infanto-juvenil e os classificam nas seguintes categorias de livros sobre negros escritos por brancos e também por autores afro-americanos: livros de "consciência social" - escritos principalmente para ajudar os brancos a se familiarizarem com a condição de seus semelhantes negros; livros "melting-pot" 22 - escritos para leitores negros e brancos para mostrar que as crianças negras não são diferentes das crianças brancas, - e livros "culturalmente conscientes" - escritos principalmente para afro-americanos. Neste sentido, os TBB é um tipo de produção literária que vai além de discutir os estereótipos e imagens negativas presentes em outras produções e propõe uma visão, uma imagem alternativa e positiva dos afro-

${ }^{21}$ The editors included a frontispiece after the table of contents which was provided by the photo agency Underwood \& Underwood (Fig. 2). The photograph shows "Her Royal Highness, Zaouditou, Queen of the Kings of Abyssinia, Empress of Ethiopia," as the children can read in the caption (TBB Jan. 1920: 2).164 The Empress is in the center of the picture, sitting on a throne made out of valuable and amply adorned cushions and blankets. Her attire is made of expensive material and is nicely decorated and embroidered. On her head, she is wearing a big crown, and she holds a scepter in her hand. The Empress is sitting in an erect position, looking gracefully to the front but not directly at the reader. This photograph introduces young African-Americans to black royalty with the intention of boosting their self-esteem because they are meant to realize that the black race can claim nobility as well.

22 Significa caldeirão ou cadinho e é uma metáfora para uma sociedade onde muitos tipos diferentes de pessoas se misturam formando supostamente um povo único. O EUA é frequentemente chamado de cadinho de povos. Uma contra-narrativa importante à noção de melting pot se encontra em Du Bois no The Souls of Black Folk, Du Bois (1903) e The Gift of Black Folk: The Negroes in the Making of America (1924), nos quais ele detalhou as imensas e originais contribuições culturais que os negros fizeram à sua comunidade, nação e ao mundo. No entanto, até muito recentemente essa contra-narrativa que desafiava as bases da ideologia do "melting pot" não foi considerada. 
americanos. Na figura $\mathrm{n}^{\mathrm{o}} 4$ o contraste entre a representação construída e amplamente consumida, a partir dos shows de menestréis, dos gollies e a imagem de garotos negros em trajes distintos a caminho da escola.

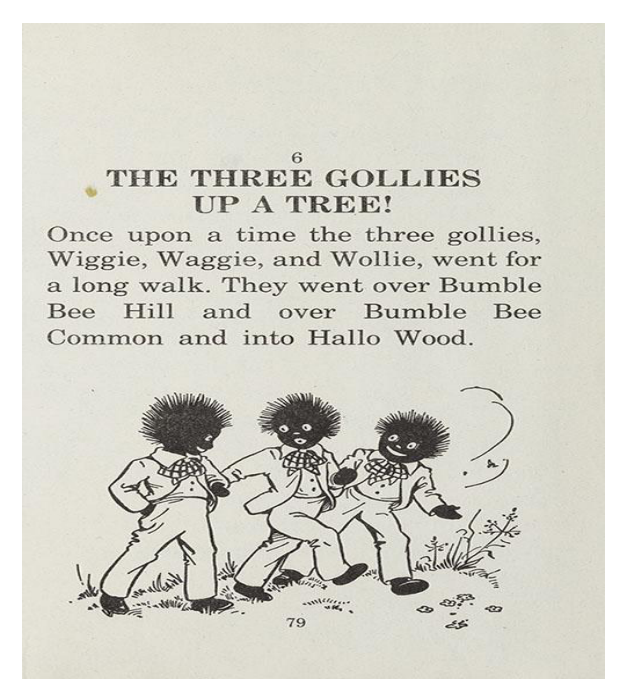

Figura 4: Three-golliwogs-enid-blytonbook-196823

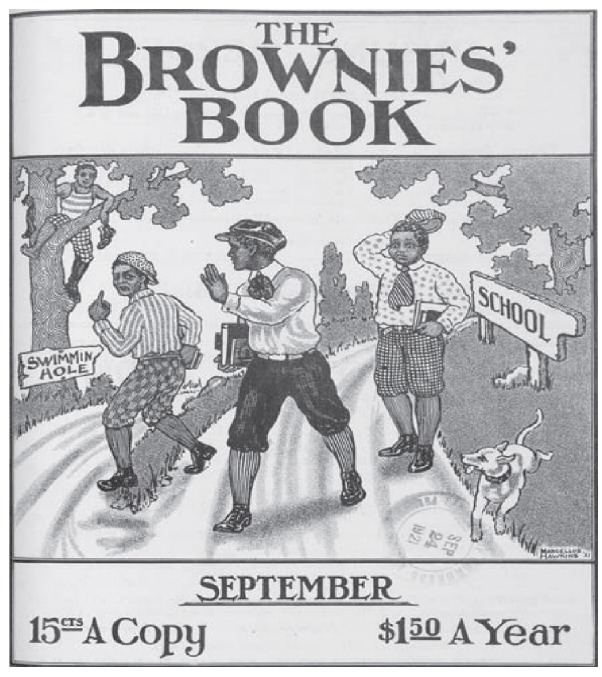

Figura 4: Cover - The Brownies' Book September 1921.

Em relação à composição de gênero e cor dos autores durante os dois anos de publicação, o periódico apresentou diversos tipos de textos de 118 autores. A maioria dos escritos era de negros e negras (95\%), o que pressupõe que tinham conhecimento dos problemas que as crianças e jovens afro-americanos enfrentavam enquanto cresciam em um ambiente predominantemente racista. Oitenta e três (70\%) eram mulheres e trinta e um (26\%) homens.

A presença duas vezes maior de mulheres na escritura dos textos publicados no TBB é relevante de diferentes maneiras: a) ela indica que para além de receptoras passivas eram escritoras ativas no processo de construção da identidade negra infanto-juvenil; b) o que pode relativizar a hipótese predominante de que era antes de tudo considerado tarefa das mulheres ficar em casa e criar os filhos; c) as mães, prioritariamente em relação aos pais, aprenderam o que se passava na cabeça de seus filhos e os problemas relacionados à auto-estima e auto-confiança e, não

\footnotetext{
${ }^{23}$ Disponível em: https://www.worthpoint.com/worthopedia/enid-blyton-book-threegolliwogs.
} 
the brownies' book: du bois e a construção de uma referência literária para identidade negra infantojuvenil

surpreendentemente, a literatura infantil acabou sendo principalmente de domínio das mulheres.

Os dois anos de publicações dos Brownies' Book demonstram tanto uma necessidade quanto um campo de possibilidades, que Du Bois e Fauset souberam identificar após a Primeira Guerra Mundial. Em contraste com a Escola de Chicago, o pressuposto de Du Bois era que os negros americanos tinham um passado que a escravidão e o colonialismo, ao construírem a África como o lugar da ausência história, primaram por tentar apagar negando a diversidade constitutiva da humanidade. Assim, Du Bois como intelectual público utilizou sua sofisticada formação acadêmica, considerando o período, para mostrar que a construção do negro como um estranho, ou um problema, era antes de tudo uma questão política que tinha consequências sociais desastrosas para o conjunto da sociedade. E, portanto, sua resolução só pode se dar no âmbito da política através do reconhecimento da contribuição dos africanos e seus descendentes para a humanidade, o que implicava socialmente assumir sua especificidade em igual condições de outras contribuições.

Em contraste com o universalismo eurocêntrico, Du Bois acreditava no pluralismo cosmopolita que professava a construção do universal com base nas contribuições particulares dos diferentes povos ou raças, espíritos ou almas, que são o substrato das identificações que constituem diferentes identidades. Neste sentido, a sociologia para ele deveria ter uma finalidade prática em um mundo no qual a hierarquia, preconceitos e discriminações é a regra.

A vida curta do TBB, considerando seu impacto positivo, não impediu a continuidade de publicações que afirmavam a supremacia branca e ridicularizava as crianças e jovens negros e negras.

É provável que o imaginário social que animalizava a criança negra tenha informado uma contínua e rentável produção literária que, aparentemente, foi baseada em uma "boneca negra menestrel" e apareceu primeiramente no livro The Adventures of two Dutch Dolls, figura n ${ }^{\circ}$, em um livro de Florence Kate Upton em $1895^{24}$.

\footnotetext{
${ }^{24}$ Disponível em: https://rareandantiquebooks.com/first-edition-books/dutch-dolls/
} 


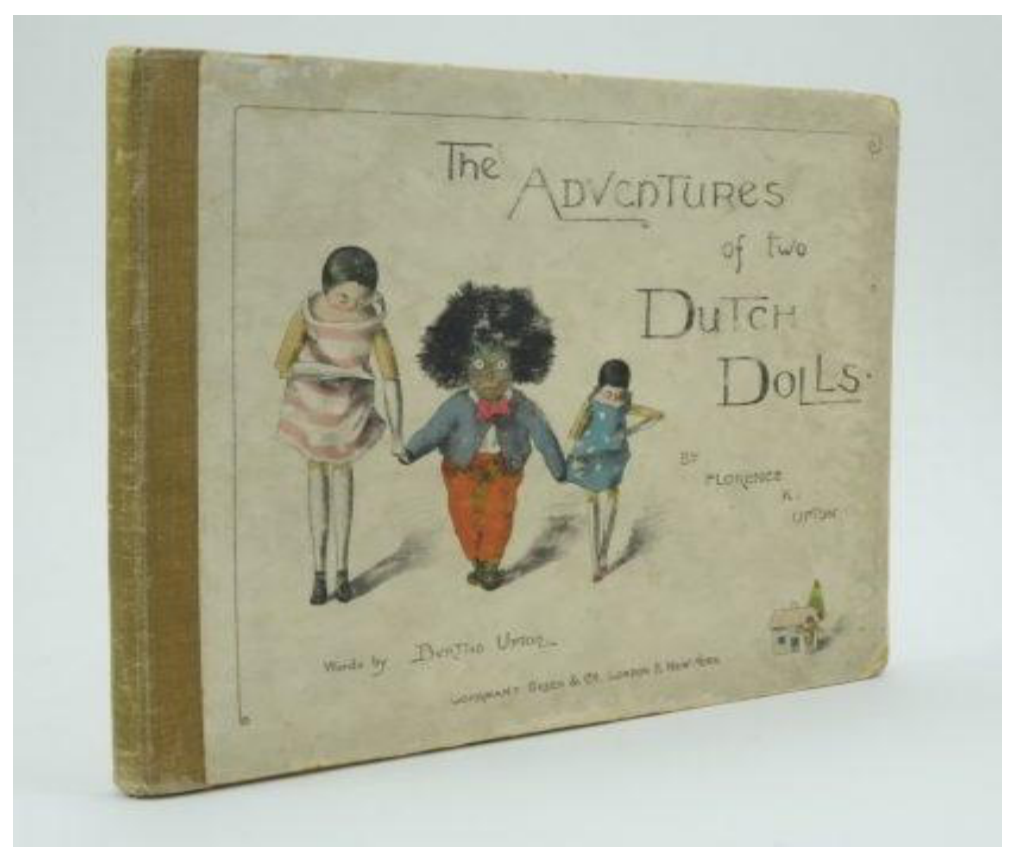

Figura 5: The Adventures of Two Dutch Dolls By F. K. Upton

O magazine The Crisis, o jornal oficial da NAACP, publicou sua primeira edição em 1910, sob o comando editorial da W.E.B. Du Bois, que na sua edição de julho de 1919 trazia um suplemento sobre linchamentos de negros e negras nos EUA. Os linchamentos em que negros foram enforcados em árvores eram corriqueiros, como os que a cantora de Jazz, Billie Holiday, a cantar tristemente: “Árvores do Sul carregam uma fruta estranha, sangue nas folhas e sangue na raiz, corpos negros balançando na brisa do Sul, estranhas frutas penduradas nos troncos das árvores". Como durante a escravidão americana, as condições pós-reconstrução levaram os ex-escravizados a cantarem: "Ninguém sabe os problemas que eu tenho vivido" 25 .

\footnotetext{
${ }^{25}$ Morris, Aldon. W. E. B. Du Bois no centro: da ciência, do movimento de direitos civis, ao movimento Black Lives Matter (Tradutores: Valter Roberto Silvério, Hasani Eliotério dos Santos e Fernando Oliveira da Costa). Revista da Associação Brasileira de Pesquisadores/as Negros/as (ABPN), [S.1.], v. 12, n. 32, p. 367-387, maio 2020. ISSN 2177-2770. Disponível em: <https://abpnrevista.org.br/index.php/site/article/view/892>

Pfeifer (2004), por exemplo, associa o declínio do linchamento no início do século XX ao advento da pena de morte moderna: "os legisladores renovaram a pena de morte... por preocupação direta com a alternativa da violência das multidões". Ele também cita "os excessos modernos e racializados das forças policiais urbanas no século XX e depois" como tendo características de linchamento.
} 
the brownies' book: du bois e a construção de uma referência literária para identidade negra infantojuvenil

Os Brownies' Books (TBB), por seu turno, representam a emergência de uma contra-literatura preocupada e especializada na constituição de valores e imagens positivas do ser negro e negra e, ao fazê-lo, colocou um novo horizonte de expectativas para as crianças afro-americanos e que pode ser um caminho a ser perseguido constantemente por outras experiências nacionais como, por exemplo, a brasileira. Segundo Fernandes e Bastide (1971, p. 283-284), atrás da cordialidade, da intimidade e mesmo da afetividade transparente nas relações sociais dos brancos com os pretos (negros), se ocultam regras sociais, cujo reconhecimento, ainda hoje, é possível. As duas regras básicas, presumivelmente, estipulavam que não seria de bom tom nem a exteriorização dos sentimentos dos brancos com relação aos pretos na presença destes; nem se isto acontecesse, que os pretos revidassem, manifestando os sentimentos reais desencadeados por semelhantes experiências. A desaprovação a ambas as condutas foi, e continua a ser em nossos dias, definida e forte. $\mathrm{O}$ adestramento para enfrentar tais situações começa, normalmente, muito cedo na família e nas escolas.

Não é estranho, portanto, que a ética oculta da indiferença em relação às diferenças funcione como uma convicção no espaço escolar a partir da creche. Embasada pela ideologia da democracia racial, ela funciona como um dos fundamentos, mesmo que ambíguo e em erosão, das práticas educativas que posicionam os sujeitos (brancos e não-brancos) em relação ao lugar que eles deverão ocupar na sociedade e, ao mesmo tempo, abrem as possibilidades, com base nas experiências individuais e coletivas vivenciadas no cotidiano, do questionamento ao discurso que tenta fixá-los. Tais questionamentos fissuram as etiquetas de tratamento que atravessam o espaço escolar e provocam a necessidade de ampliar o espaço da "diferença", a qual ainda é traduzida pelos educadores como diversidade ${ }^{26}$.

\footnotetext{
${ }^{26}$ Silvério, V. R. e Rodrigues, T. C. Pp.187-188. Movimento negro, educação e diáspora: em busca de uma pedagogia da emancipação. In: Faria, A.L.G et al. (org.) Infâncias e pós-colonialismo: pesquisas em busca de pedagogias descolonizadoras. Campinas: Leitura Crítica, 2015.
} 


\section{sobre a importância contemporânea da proposta de du bois}

Como parte da obra, reflexão e ação política de Du Bois, os Brownie's Book se constituiu em um exemplo da maneira como se poderia oferecer uma identificação positiva, para as crianças e jovens negros e negras, em direção à mudança social qualitativa no início da terceira década do século XX. Em uma análise inicial dos dois anos de publicações dos TBB, podemos concluir que a sua perspectiva metodológica tinha como orientação a reapropriação crítica do passado, tornando a condição de escravizado um valor, nos termos de Du Bois 1974, p. 8990) ${ }^{27}$ :

[...] uma compreensão daquele passado, do qual nos envergonhamos por longos anos, pelo qual nos desculpamos. Pensamos que nada poderia sair daquele passado que queríamos lembrar; que queríamos transmitir aos nossos filhos. De repente, esse mesmo passado vai ganhando forma, cor e realidade, e de um modo meio envergonhado começamos a nos orgulhar dele.

Ao propor o pluralismo cultural e o transnacionalismo, Du Bois não apenas encorajava a ideia de identidades hifenizadas (afro-americano, africano-americano, afro-brasileiro), ele foi um dos pioneiros a pensar o que podemos chamar atualmente de dupla cidadania. Além de se considerarem africanos e americanos orgulhosos, Du Bois também queria que as crianças negras aprendessem desde cedo os limites da cidadania nacional e se considerassem cidadãs do mundo ou cosmopolitas. Ele acreditava que "os negros deveriam dar o exemplo de amplitude" e promoverem o ideal de fraternidade humana por meio da afirmação do seu pertencimento "racial" não apenas no interior das fronteiras dos Estados Unidos e sim em uma perspectiva global (TBB maio 1920, p. 139).

Uma África reconfigurada e desvencilhada dos estigmas e preconcepções de inferioridade eurocêntricas se constituía em uma nova possibilidade de identificação positiva de origem. Nos termos de Du Bois, era o passado utilizável com o qual os afro-americanos poderiam criar uma memória cultural e política negro-africana com a esperança de dias melhores em direção ao futuro. Nos termos da época, uma visão dinâmica de uma grande comunidade (negra) mundial.

\footnotetext{
${ }^{27}$ W.E.B. Du Bois, “The Negro in Literature and Art," In: A W.E.B. Du Bois Reader. New York: Macmillan, 1974. p. 89-90.
} 
the brownies' book: du bois e a construção de uma referência literária para identidade negra infantojuvenil

Caberia acrescentar nos dias que se seguem uma comunidade global que reconheça a diferença enquanto constitutiva da humanidade.

\section{referências}

Black History in America. Jessie Fauset, BHA, s/d. Acesso em: 02 maio 2021. Disponível em: http://www.myblackhistory.net/Jessie_Fauset.htm

Crisis. A Record of the Darker Races. Vol. 1, No. 1, Du Bois, W. E. Burghardt (editor) New York: National Association for the Advancement of Colored People, 1910-11 / 192212. https:// modjourn.org/journal/crisis/

Diggs, I. DuBois and Children, Phylon (1960-), vol. 37, No. 4 (4th Qtr., 1976), pp. 370-399, Published by: Clark Atlanta University, URL: https://www.jstor.org/stable/274501

Du Bois, W.E.B. “Strivings of the Negro People. Atlantic Monthly, August, 194-97, 1897b.

Du Bois, W.E.B. As almas da gente negra. Rio de Janeiro: Lacerda Editores, 1999. Tradução, introdução e notas, Heloisa Toller Gomes.

Du Bois, W.E.B. The Gift of Black Folk: The Negroes in the Making of America [1924]. Oxford: The Oxford University Press, 2014.

Du Bois, W.E.B. "The Negro in Literature and Art," 1913, A W.E.B. Du Bois Reader (New York: Macmillan, 1974, print) 89-90.

Du Bois, W.E.B. As Almas da Gente Negra. Tradução de Gomes. Rio de Janeiro: Lacerda Editores, 1999.

Du Bois, W.E.B. Primary Source - The Atlanta Conferences. Acesso em: 02 maio 2021. Disponível em: http://www.webdubois.org/dbAtlantaConfs.html

Fernandes, F. e Bastide, R. Brancos e negros em São Paulo: ensaio sociológico sobre aspectos da formação, manifestações atuais e efeitos do preconceito de cor na sociedade paulistana. (3a Ed.) São Paulo: Companhia Editora Nacional, 1971.

Gikandi, Simon. W. E. B. DuBois and the Identity of Africa. GEFAME Journal of African Studies, vol. 2, no. 1, 2005. http://hdl.handle.net/2027/spo.4761563.0002.101

Hopkins, P. E. Contending Forces: a romance illustrative of Negro life North and South, 1900, by Pauline E. Hopkins. Oxford: Oxford UP, 1988.

Liss, Julia. Diasporic Identities: The Science and Politics of Race in the Work of Franz Boas and W. E. B. Du Bois, 1894-1919. Cultural Anthropology 13(2): 127-166, 1998, American Anlhropological Association.

Locke, A. The New Negro: Voices of the Harlem Renaissance, New York: Touchstone, 1997.

Morris, Aldon. W. E. B. Du Bois no centro: da ciência, do movimento de direitos civis, ao movimento Black Lives Matter. (Tradutores: Valter Roberto Silvério, Hasani Eliotério dos Santos e Fernando Oliveira da Costa). Revista da Associação Brasileira de Pesquisadores/as Negros/as (ABPN), [S.1.], v. 12, n. 32, p. 367-387, maio 2020. ISSN 2177-2770. Disponível em: <https://abpnrevista.org.br/index.php/site/article/view/892

Oh Golly: A Brief History Of The Golliwog.By Ed Barrett (FLASHBAK), February 8, 2009. Acesso em: 02 maio 2021. Disponível em: https:/ /flashbak.com/oh-carolthatcher-oh-golly-a-brief-history-of-the-golliwog-2-16682/

Omlinson, Susan. "Teaching Jessie Fauset's Plum Bun." In Teaching the Harlem Renaissance: Course Design and Classroom Strategies. Edited by Michael Soto, 115-121. New York: Peter Lang, 2008.

Pfeifer, Michael J. Rough justice: lynching and American Society, 1874-1947. Illinois: University of Illinois Press, 2004. 
Racism, Representation, and Resistance in children's literature 1800-2015. Curated by Suzan Alteri, Stephanie Birch, and Dr. Hélène Huet (George A. Smathers Libraries University of Florida), Gainesville, FL 32603, United State, August 13 - October 5, 2018. Acesso em: 02 maio 2021. Disponível em: https:/ / exhibits.uflib.ufl.edu/RacismRepresentation/racist-portrayals.html

Sachäffer, Christina. The Brownies' Book: Inspiring Racial Pride in African-American Children. Frankfurt am Main: Peter Lang, 2012.

Silvério, V.R. O programa Brasil-África na construção da ideia de diáspora africana. Revista do PPGCS - UFRB - Novos Olhares Sociais | Vol.1 - n.1 - 2018, p. 131-162.

Special Issue. One Hundred Years of The Souls of Black Folk: A Celebration of W. E. B. Du Bois. Public Culture, volume 17, issue 2, spring de 2005.

Vaughn-Roberson and HILL. "The Brownies' Book and Ebony Jr.!: Literature as a Mirror of the Afro-American Experience". The Journal of Negro Education, 58(4), 494-510, 1989.

Wall, Cheryl. Women of the Harlem Renaissance. Bloomington: Indiana University Press, 1995.

Williams, Robert W. "Embracing Philosophy: On Du Bois' 'The Individual and Social Conscience'", Phylon, Fall 2014, Vol. 51, No. 1, pp. 42-56.

William-Sanchez, V.L. The Brownies' Book. The Reading Professor: Vol. 42: Iss. 1, 2019, Article 5. Available at: https://scholar.stjohns.edu/thereadingprofessor/vol42/iss1/5

recebido em: 15.03 .2021

aprovado em: 06.07.2021 